\title{
What is the Prostate-Specific Antigen Cut-Off Value to Detect Clinically Significant Prostate Cancer According to Age in Turkey?
}

\author{
(D) Turgay Ebiloğlu MD, (1) Engin Kaya MD \\ 'University of Health Sciences, Gülhane Training and Research Hospital, Clinic of Urology, Ankara, Turkey
}

\begin{abstract}
Objective: To detect a prostate-specific antigen (PSA) cut-off for clinically significant prostate cancer (csPCa) according to age in Turkey.

Materials and Methods: A total of 532 men who had transrectal ultrasound-guided biopsy of the prostate due to elevated PSA and abnormal findings on digital rectal examination between January 2011 and January 2018 were retrospectively evaluated. Elevated PSA was defined as $\geq 4 \mathrm{ng} / \mathrm{mL}$. Patients were divided into groups $1-5$ according to age: $40-49,50-59,60-69,70-79$, and $\geq 80$ years. A PSA cut-off value was determined for each group.

Results: The mean age was 66.45 \pm 8.21 (41-89) years. There were 20, 112, 222, 154, and 24 patients in groups 1-5, respectively. Mean PSA values were $6.04 \pm 3.88(0.24-16.46) \mathrm{ng} / \mathrm{mL}, 6.8 \pm 4.17(0.97-35.07) \mathrm{ng} / \mathrm{mL}, 10.51 \pm 8.53(0.72-128.5) \mathrm{ng} / \mathrm{mL}, 20.41 \pm 36.64(1.32-250) \mathrm{ng} / \mathrm{mL}$, and $73.28 \pm 100.19$ (9.33-344.1) ng/mL in groups 1-5, respectively. PSA cut-off values for csPCa were $7.08 \mathrm{ng} / \mathrm{mL}, 4.71 \mathrm{ng} / \mathrm{mL}, 7.30 \mathrm{ng} / \mathrm{mL}, 8.12 \mathrm{ng} / \mathrm{mL}$, and $14.12 \mathrm{ng} / \mathrm{mL}$ in groups $1-5$, respectively.

Conclusion: There is a correlation between PSA and age in Turkey. Using the PSA cut-off values determined in our study would decrease the number of unnecessary biopsy procedures.
\end{abstract}

Keywords: Prostate specific antigen, Turkey, prostate cancer

\section{Introduction}

Prostate cancer (PCa) has the highest annual incidence rate of all cancers in men and is the second leading cause of cancer deaths in men following small cell lung cancer. After prostate-specific antigen (PSA) was first described by Catalona et al. (1) in 1991, the rate of $\mathrm{PCa}$ detection increased dramatically. The United States Food and Drug Administration approved the use of PSA for cancer detection in 1994 (2). For PSA levels of $1-4 \mathrm{ng} / \mathrm{mL}$, its sensitivity and specificity values in PCa detection have been reported as $83 \%$ and $38 \%$ at PSA: $1 \mathrm{ng} / \mathrm{mL} ; 52 \%$ and $72 \%$ at 3.1 $\mathrm{ng} / \mathrm{mL}$ PSA, $32 \%$ and $86 \%$ at $1 \mathrm{ng} / \mathrm{mL}$ PSA, and $20 \%$ and $94 \%$ at $4.1 \mathrm{ng} / \mathrm{mL}$ PSA, respectively (2). According to these values, using a low threshold value will result in a higher PCa detection rate. However, the rate of detection of clinically insignificant cancers will also increase. A low threshold value will also result in low specificity values, which will not allow PCa exclusion.

Various PSA threshold values are used worldwide. Among previous studies with large patient numbers, a threshold value of 2.5 or $3.0 \mathrm{ng} / \mathrm{mL}$ was used in the European Randomized Study of Screening for Prostate Cancer (ERSPC) (3) and a threshold of $4.0 \mathrm{ng} / \mathrm{mL}$ was used in the Prostate, Lung, Colorectal, and Ovarian Cancer Screening Trial (PLCO) conducted in the United States of America (USA) (4). In the Swedish arm of the ERSPC, referred to as the Göteborg Trial, $3.4 \mathrm{ng} / \mathrm{mL}$ was used between 1993-1998, after which a value of $2.5 \mathrm{ng} / \mathrm{mL}$ was used (5). In 
1993, Oesterling et al. (6) investigated PSA threshold values for PCa based on age in 537 American subjects and reported PSA threshold values of $2.5 \mathrm{ng} / \mathrm{mL}, 3.5 \mathrm{ng} / \mathrm{mL}, 4.5 \mathrm{ng} / \mathrm{mL}$, and 6.5 $\mathrm{ng} / \mathrm{mL}$ respectively for the $40-49,50-59,60-69$, and $70-79$ age groups.

It is apparent that each country uses its own threshold values for the detection of PCa. However, the determined PSA threshold values are not intended for the detection of clinically significant PCa (csPCa), but for the general detection of PCa. Our aim in this study was to determine age-specific PSA threshold values to be used for the detection of cSPCa in Turkey.

\section{Materials and Methods}

Following approval (no: 18/44) by the University of Health Sciences, Gülhane Training and Research Hospital Ethics Committee, statistical power analysis indicated that 385 patients were necessary to conduct the study. Consent was obtained from the patients. Data pertaining to 532 consecutive patients who had elevated PSA levels or abnormal findings on digital rectal examination (DRE) and underwent transrectal ultrasoundguided biopsy of the prostate (TRUSbP) between January 2011 and January 2018 were evaluated retrospectively. PSA elevation was defined as PSA $\geq 4 \mathrm{ng} / \mathrm{mL}$. Patients with elevated PSA levels were treated with oral antibiotherapy for two weeks to rule out the possibility of bacterial prostatitis. Then a second blood sample was taken to determine whether the PSA elevation persisted. Free PSA measurement was also done in this session. Patients with persistent PSA elevation were referred for TRUSbP. Patients with life expectancy $<10$ years were not subjected to TRUSbP.

TRUSbP was performed using a special ultrasound device that acquires both axial and sagittal images (Logiq 5). At least 12 prostate biopsy cores were obtained using an 18-gauge Tru-Cut (UK Medical) prostate needle.

Patients with PSA $\leq 10 \mathrm{ng} / \mathrm{mL}$, Gleason (G) score $\leq 3+3$, and $\leq 2$ tumor-containing cores were considered to have clinically insignificant PCa (ciPCa). Patients with values higher than these were diagnosed with csPCa.

Patients were classified by age as group 1: 40-49 years, group 2: 50-59 years, group 3: 60-69 years, group 4: 70-79 years, and group 5: $\geq 80$ years. PSA threshold values were determined for the detection of PCa and CsPCa within these age groups. Following the determination of PSA threshold values for PCa and CSPCa, a free/total PSA ratio threshold was determined for the PSA range between those two PSA values.

\section{Statistical Analysis}

"Statistical Package for Social Sciences 20.0 (SPSS 20.0 for Mac OS)" software package was used for statistical analyses. Descriptive statistics were presented using mean (minimummaximum) values, frequencies, and percentages. KolmogorovSmirnov, Shapiro-Wilk, and Skewness and Kurtosis tests were used to evaluate whether the data conformed to a normal distribution. The Pearson correlation test was used to evaluate correlations between continuous variables. Receiver operating characteristic (ROC) curves were generated for each age group based on PSA level. These ROC curves were used to determine
PSA threshold values for the detection of PCa and CsPCa. $\mathrm{P}<0.05$ was defined as statistically significant.

\section{Results}

Data from a total of 532 patients were analyzed. Mean age of the patients was $66.45 \pm 8.21(41-89)$ years. Their mean and median PSA values were 15.13 \pm 5.21 (0.29-344.1) ng/ $\mathrm{mL}$ and $7.25 \mathrm{ng} / \mathrm{mL}$. Groups 1, 2, 3, 4, and 5 consisted of 20, $112,222,154$, and 24 patients, respectively. The mean PSA values in these age groups were $6.04 \pm 3.88(0.24-16.46) \mathrm{ng} /$ $\mathrm{mL}, 6.8 \pm 4.17(0.97-35.07) \mathrm{ng} / \mathrm{mL}, 10.51 \pm 8.53(0.72-128.5)$ $\mathrm{ng} / \mathrm{mL}, 20.41 \pm 36.64(1.32-250) \mathrm{ng} / \mathrm{mL}$, and $73.28 \pm 100.19$ (9.33-344.1) $\mathrm{ng} / \mathrm{mL}$, respectively (Figure 1 ). PSA level at time of PSA elevation detection was positively correlated with age $(p=0.001)$.

In group 1, TRUSbP revealed $\mathrm{PCa}$ in 6 patients, ciPCa in 1 patient $(17 \%)$ and csPCa in 5 patients (83\%). A detailed examination of the pathology results revealed $\mathrm{G} 3+3 \mathrm{PCa}$ in 3 patients (50\%) and $\mathrm{G} 3+4 \mathrm{PCa}$ in 3 patients (50\%) (Table 1). In ROC curve analyses, areas under the curve for $\mathrm{PCa}$ and csPCa detection were $0.480(p=0.903)$ and $0.889(p=0.043)$, respectively, and PSA thresholds were determined as $2.21 \mathrm{ng} /$ $\mathrm{mL}$ for PCa detection and $7.08 \mathrm{ng} / \mathrm{mL}$ for csPCa detection (values providing $>80 \%$ sensitivity) (Table 2 ). A free/total PSA ratio threshold value for detecting csPCa at PSA values between these thresholds could not be calculated due to the small number of patients.

In group 2, TRUSbP revealed PCa in 22 patients, ciPCa in 10 patients (45\%) and csPCa in 12 patients (55\%). Pathology results indicated histological grade of $\mathrm{G} 3+3$ in 12 patients, G3+4 in 2 patients, G3+5 in 1 patient, G4+3 in 1 patient, G4+4 in 1 patient, G4+5 in 1 patient, G5+3 in 2 patients, G5+4 in 1 patient, and $\mathrm{G} 5+5$ in 1 patient (Table 1 ). In ROC curve analyses, areas under the curve for $\mathrm{PCa}$ and csPCa detection were 0.526 $(p=0.068)$ and $0.621(p=0.209)$, respectively, and PSA threshold values were determined as $4.15 \mathrm{ng} / \mathrm{mL}$ for $\mathrm{PCa}$ detection

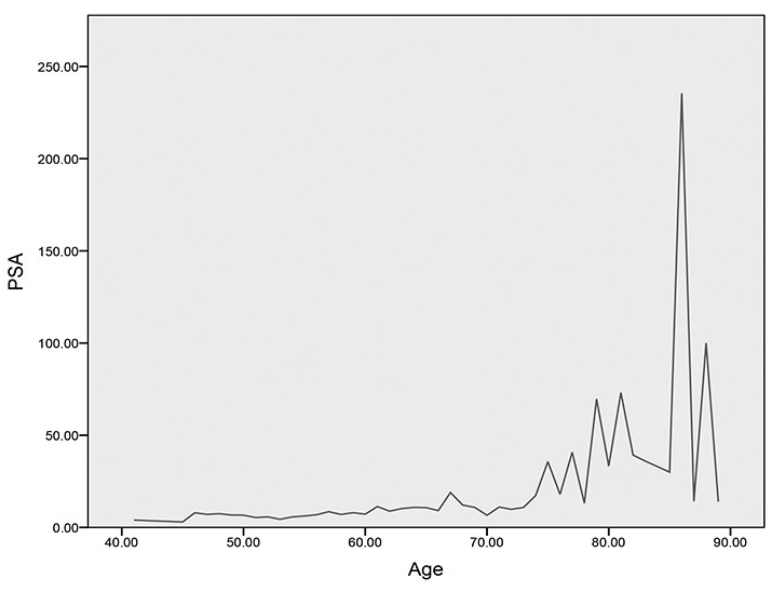

Figure 1. Age-related change in prostate-specific antigen in the presence of prostate cancer in Turkey

PSA: Prostate-specific antigen 


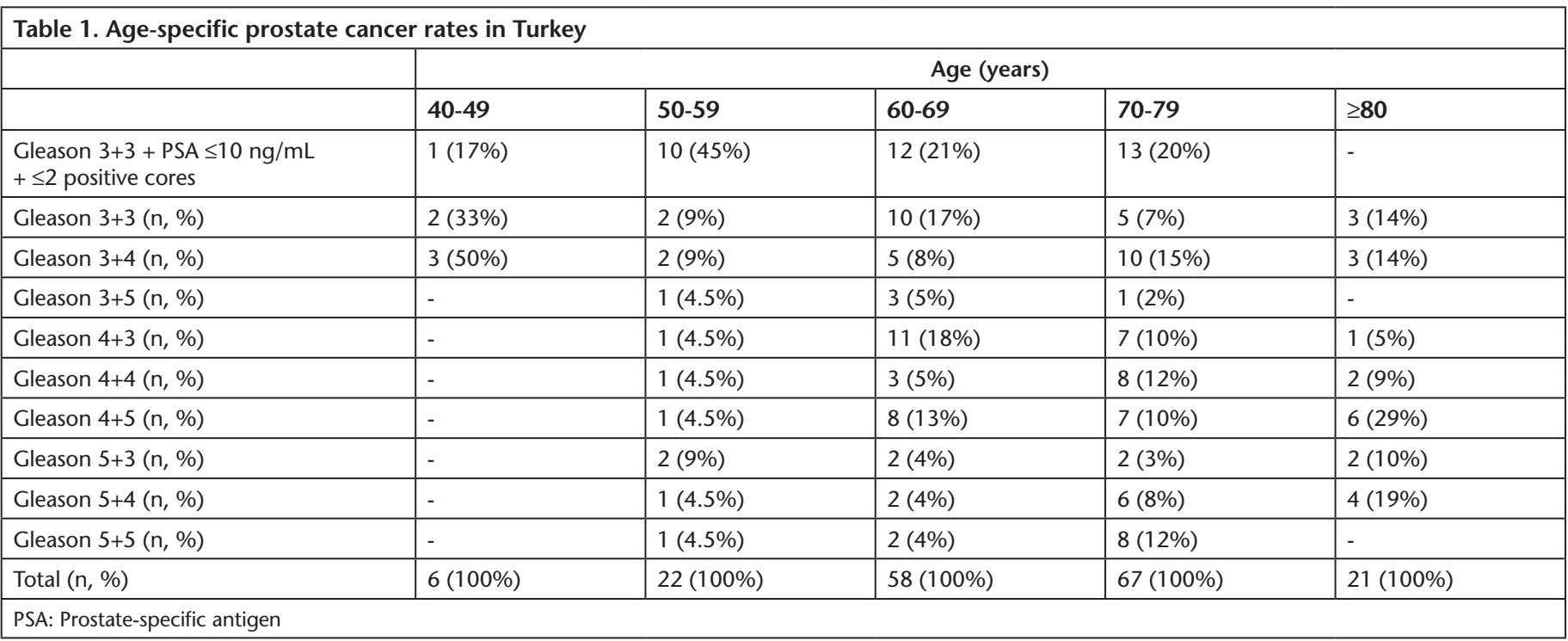

and $4.71 \mathrm{ng} / \mathrm{mL}$ for csPCa detection (values providing $>80 \%$ sensitivity) (Table 2). A free/total PSA ratio threshold value for detecting csPCa at PSA values between these thresholds could not be calculated due to the small number of patients.

In group 3, TRUSbP revealed $\mathrm{PCa}$ in 58 patients, ciPCa in 12 patients (21\%) and csPCa in 46 patients (79\%). Detailed evaluation of pathology results revealed histological grade of $\mathrm{G} 3+3$ in 22 patients, $\mathrm{G} 3+4$ in 5 patients, $\mathrm{G} 3+5$ in 3 patients, $\mathrm{G} 4+3$ in 11 patients, G4+4 in 3 patients, G4+5 in 8 patients, G5+3 in 2 patients, G5+4 in 2 patients, and G5+5 in 2 patients (Table 1). In ROC curve analyses, areas under the curve for $\mathrm{PCa}$ and csPCa detection were $0.681(\mathrm{p}=0.01)$ and $0.782(\mathrm{p}=0.001)$, respectively, and PSA threshold values were $6.06 \mathrm{ng} / \mathrm{mL}$ for PCa detection and $7.3 \mathrm{ng} / \mathrm{mL}$ for csPCa detection (values providing $>80 \%$ sensitivity) (Table 2 ). The insufficient number of patients in this group also precluded determination of a free/total PSA ratio threshold value for detecting csPCa at PSA values between these thresholds.

In group 4, TRUSbP revealed PCa in 67 patients, ciPCa in 13 patients (20\%) and csPCa in 54 patients (80\%). Histological grade according to pathology was $\mathrm{G} 3+3$ in 18 patients, $\mathrm{G} 3+4$ in 10 patients, G3+5 in 1 patient, G4+3 in 7 patients, G4+4 in 8 patients, G4+5 in 7 patients, G5+3 in 2 patients, G5+4 in 6 patients, and G5+5 in 8 patients (Table 1). In ROC curve analyses, areas under the curve for PCa and csPCa detection were $0.678(p=0.001)$ and $0.776(p=0.001)$, respectively, and PSA threshold values were determined as $6.12 \mathrm{ng} / \mathrm{mL}$ for $\mathrm{PCa}$ detection and $8.12 \mathrm{ng} / \mathrm{mL}$ for csPCa detection (values providing $>80 \%$ sensitivity) (Table 2). The free/total PSA ratio threshold value for the detection of CSPCa for PSA values between those thresholds was determined to be 0.18 (value providing $>80 \%$ sensitivity).

In group 5, TRUSbP revealed PCa in 21 patients, all of which were csPCa. Histological grade was $\mathrm{G} 3+3$ in 3 patients, $\mathrm{G} 3+4$ in 3 patients, G4+3 in 1 patient, G4+4 in 2 patients, G4+5 in 6 patients, G5+3 in 2 patients, and G5+4 in 4 patients (Table 1). ROC curve analysis showed that the area under the

\begin{tabular}{|c|c|c|}
\hline & PSA threshold value & \\
\hline Age (years) & Prostate cancer $(\mathrm{ng} / \mathrm{mL})$ & $\begin{array}{l}\text { Clinically significant } \\
\text { prostate cancer }(\mathrm{ng} / \mathrm{mL})\end{array}$ \\
\hline $40-49$ & 2.21 & 7.08 \\
\hline $50-59$ & 4.15 & 4.71 \\
\hline $60-69$ & 6.06 & 7.30 \\
\hline $70-79$ & 6.12 & 8.12 \\
\hline$\geq 80^{*}$ & - & 14.12 \\
\hline
\end{tabular}

curve was $0.775(p=0.209)$ and the PSA threshold value was $14.12 \mathrm{ng} / \mathrm{mL}$ for the detection of csPCa (values providing $>80 \%$ sensitivity) (Table 2). Free/total PSA ratio threshold value for csPCa detection could not be determined due to the small number of patients.

\section{Discussion}

The introduction of PSA by Catalona et al. (1) in 1991 resulted in a rapid increase in rates of $\mathrm{PCa}$ detection. Following that discovery, large studies related to PSA were planned. The ERSPC commenced in Europe in the same year, and the USA initiated the PLCO Cancer screening trial in 1994. These are the studies currently providing the most extensive information on the utility of PSA monitoring. Another study that also offered valuable data about PSA reported its results around the same time. In a study published by Oesterling et al. (6) in 1993, 2119 healthy males were evaluated between 1989 and 1991 and 471 of the men underwent prostate biopsy. Blood PSA levels were measured and evaluated according to age. They determined that PSA was correlated with age and identified PSA threshold values for $\mathrm{PCa}$ detection as $2.5 \mathrm{ng} / \mathrm{mL}, 3.5 \mathrm{ng} / \mathrm{mL}$, $4.5 \mathrm{ng} / \mathrm{mL}$, and $6.5 \mathrm{ng} / \mathrm{mL}$ for the age ranges of $40-49,50-59$, 60-60, and 70-79 years, respectively (6). In 1994, Catalona 
et al. (7) accepted $>4 \mathrm{ng} / \mathrm{mL}$ as the PSA threshold value and investigated its combined use with DRE for the detection of PCa in 6630 volunteers over the age of 50 years. PSA elevation was detected in $15 \%$ of the patients, suspicious lesions were detected on DRE in $15 \%$, and both findings were detected in $26 \%$ of the patients. PCa detection rates for PSA, DRE, and PSA + DRE were reported to be $4.6 \%, 3.2 \%$, and $5.8 \%$, respectively (7). In 1998, Catalona et al. (8) investigated free/total PSA ratio and reported a threshold value of $25 \%$ for the detection of PCa in patients with PSA levels of $4-10 \mathrm{ng} / \mathrm{mL}$. Trials that began in Europe and the USA in the 1990s began to publish results at the end of the 2000s. In the ERSPC, 162,387 European men were divided into 2 groups, one which underwent PSA screening yearly for 4 years and another which did not undergo screening. Using a PSA threshold value of 2.5 or $3.0 \mathrm{ng} / \mathrm{mL}$, the rate of PCa detection was reported to be $8.2 \%$ in the PSA screening group and $4.8 \%$ in the non-screened group after 9 years of follow-up (3). After 13 years of follow-up, PCa mortality in the screened group was $21 \%$ lower than in the non-screened controls (5). In the PLCO trial, 76,693 men were divided into 2 groups, one which underwent PSA screening yearly for 6 years and a non-screened control group. A PSA threshold value of $4.0 \mathrm{ng} / \mathrm{mL}$ was used, and after 7 years of follow-up, the rate of PCa detection was reported to be $116 / 10,000$ in the PSA screening group and 95/10,000 in the control group. PCa mortality rate was $3.7 / 10,000$ in the screened group and $3.4 / 10,000$ in the control group. Differences between the groups were not statistically significant for either evaluation (5). Considering all of these studies together, it is clear that although PSA is integral to current PCa screening, there is no definite PSA threshold value for the detection of PCa. PSA threshold values seem to be determined regionally for each country or continent, and studies are designed according to these values. There are no previous publications that evaluate age-specific PSA threshold values for the detection of PCa, especially csPCa, in Turkey. Therefore, we consider our study to make a valuable contribution to the literature. We also observed a statistically significant positive correlation between PSA level and age in our study. This increase is particularly steep in men over the age of 70. In our study, the age-specific PSA threshold values for the detection of PCa were $2.21 \mathrm{ng} / \mathrm{mL}, 4.15 \mathrm{ng} / \mathrm{mL}, 6.06 \mathrm{ng} / \mathrm{mL}$, $6.12 \mathrm{ng} / \mathrm{mL}$, and $14.12 \mathrm{ng} / \mathrm{mL}$ for the respective age ranges of 40-49, 50-59, 60-69, 70-79, and $\geq 80$ years.

Research analyzing both PSA and prostatectomy specimens will obviously yield the best evidence regarding the detection of csPCa. In one such study conducted in 2006, Loeb et al. (9) reported that $10 \%$ of patients who underwent radical prostatectomy were actually clinically insignificant cases. Recent studies have focused on the detection of csPCa in particular, but analyses of the aforementioned large studies in terms of csPCa have not yet been published. Instead, multiparametric magnetic resonance imaging (MRI) has been used in recent years in an attempt to detect csPCa. Siddiqui et al. (10) reported in a study of 1003 patients that MRI-guided biopsy increased detection rates of high-risk PCa and decreased detection rates of low-risk PCa. However, MRI is an expensive laboratory technique, and determining new PSA threshold values for csPCa should be considered as a more reasonable and inexpensive alternative to using MRI. In our study, the 40-49, 50-59, 60-69, 70-79, and $\geq 80$ year age groups had csPCa ratios of $83 \%, 55 \%, 79 \%$, $80 \%$, and $100 \%$ and age-specific PSA threshold values for PCa detection of $7.08 \mathrm{ng} / \mathrm{mL}, 4.71 \mathrm{ng} / \mathrm{mL}, 7.30 \mathrm{ng} / \mathrm{mL} 8.12 \mathrm{ng} /$ $\mathrm{mL}$, and $14.52 \mathrm{ng} / \mathrm{mL}$, respectively. In short, the probability of having csPCa increases with age, and PSA threshold values also follow a rising trend. The use of the age-specific PSA threshold values determined in this study will prevent unnecessary biopsies.

For uncertain cases with PSA values between the threshold values that we determined for $\mathrm{PCa}$ and $\mathrm{CSPCa}$, we thought of using free/total PSA ratio as a marker. However, we were unable to perform calculations for the 40-49, 50-59, 60-69, and $\geq 80$ age groups because the patient numbers were insufficient. We determined a free/total PSA ratio threshold value of $18 \%$ for the 70-79 year age group.

Assessing area under the curve in ROC curve analysis is another method of showing how useful a test is. Studies involving ROC curve analysis are generally intended to evaluate the role of PSA in the detection of PCa. ROC areas under the curve for PSA have been reported as 0.63 by Wang et al. (11), 0.83 by Ma et al. (12), and 0.80 by Lee et al. (13). No previous studies have examined the ROC area under the curve based on age. The areas under the curve in our ROC curve analyses using PSA for PCa detection were $0.480,0.526,0.681,0.678$, and 0.775 for the age ranges of $40-49,50-59,60-69,70-79$, and $\geq 80$ years, respectively. This shows that the use of PSA for the detection of PCa becomes increasingly significant with age, and consistent with the literature, leads to the conclusion that PSA is important for PCa detection. Furthermore, there are no studies in the literature that evaluate the ROC area under the curve with the aim of detecting csPCa. Our study is a first in the international literature in this respect. In our study, the areas under the curve in ROC curves created using PSA for the detection of csPCa were $0.889,0.621,0.782,0.776$, and 0.775 for the age ranges of $40-49,50-59,60-69,70-79$, and $\geq 80$ years, respectively. Thus, we have shown that the area under the curve is larger when using PSA for the detection of CSPCa rather than PCa, and that the use of PSA for CSPCa is more meaningful.

\section{Study Limitations}

The most important limitations of this study are its retrospective design and the small number of patients, especially in the 40-49 years and $\geq 80$ years age groups. Another limitation is that although the literature emphasizes the importance of detecting csPCa, PSA is still used for PCa screening. For this reason, the use of PSA solely for csPCa is controversial. The fact that our study was conducted in the province of Ankara and does not directly represent the whole of Turkey can be considered another limitation. However, according to population data, the Ankara province receives the most immigration after Istanbul. Therefore, we believe the province of Ankara provides a good reflection of Turkey overall, and the title was written accordingly. 


\section{Conclusion}

PSA levels increase with age in Turkey, and using the PSA threshold values determined in this study for the detection of csPCa may prevent unnecessary biopsies.

\section{Ethics}

Ethics Committee Approval: Approval was obtained from the University of Health Sciences, Gülhane Training and Research Hospital Ethics Committee (no: 18/44).

Informed Consent: It was obtained from the patients.

Peer-review: Externally peer-reviewed.

\section{Authorship Contributions}

Surgical and Medical Practices: E.K., Concept: T.E., Design: T.E., Data Collection or Processing: E.K., Analysis or Interpretation: T.E., Literature Search: E.K., Writing: T.E., E.K.

Conflict of Interest: No conflict of interest was declared by the authors.

Financial Disclosure: The authors declared that this study received no financial support.

\section{References}

1. Catalona WJ, Smith DS, Ratliff TL, et al. Measurement of prostatespecific antigen in serum as a screening test for prostate cancer. $\mathrm{N}$ Engl J Med 1991;324:1156-1161.

2. Nogueira L, Corradi R, Eastham JA. Other biomarkers for detecting prostate cancer. BJU Int 2011;105:166-169.

3. Schröder FH, Hugosson J, Roobol MJ, et al. Screening and prostatecancer mortality in a randomized European study. $\mathrm{N}$ Engl J Med $2009 ; 26 ; 360: 1320-1328$.
4. Andriole GL, Crawford ED, Grubb RL 3rd, et al. Mortality results from a randomized prostate-cancer screening trial. $N$ Engl J Med 2009;26;360:1310-1319.

5. Schröder FH, Hugosson J, Roobol MJ, et al. Screening and prostate cancer mortality: results of the European Randomised Study of Screening for Prostate Cancer (ERSPC) at 13 years of follow-up. Lancet 2014;6;384:2027-2035.

6. Oesterling JE, Jacobsen SJ, Chute CG, et al. Serum prostatespecific antigen in a community-based population of healthy men. Establishment of age-specific reference ranges. JAMA 1993;18;270:860-864.

7. Catalona WJ, Richie JP, Ahmann FR, et al. Comparison of digital rectal examination and serum prostate specific antigen in the early detection of prostate cancer: results of a multicenter clinical trial of 6,630 men. J Urol 1994;151:1283-1290.

8. Catalona WJ, Partin AW, Slawin KM, et al. Use of the percentage of free prostate-specific antigen to enhance differentiation of prostate cancer from benign prostatic disease: a prospective multicenter clinical trial. JAMA 1998;20;279:1542-1547.

9. Loeb S, Gonzalez CM, Roehl KA, et al. Pathological characteristics of prostate cancer detected through prostate specific antigen based screening. J Urol 2006;175:902-906.

10. Siddiqui MM, Rais-Bahrami S, Turkbey B, et al. Comparison of MR/ ultrasound fusion-guided biopsy with ultrasound-guided biopsy for the diagnosis of prostate cancer. JAMA 2015;27;313:390-397.

11. Wang R, Chinnaivan AM, Dunn RL, et al. Rational approach to implementation of prostate cancer antigen 3 clinical care. Cancer 2009;115:3879-3886.

12. Ma Q, Yang DR, Xue BX, et al. Transrectal real-time tissue elastography targeted biopsy coupled with peak strain index improvest the detection of clinically important prostate cancer. Oncol Lett 2017;14:210-216.

13. Lee JG, Bae SH, Choi SH, et al. Role of prostate-specific antigen ratio initial biopsy as a novel decision making marker repeat prostate biopsy. Korean J Urol 2012;53:467-471. 